\title{
Identification of the First SARS-CoV-2 Lineage B.1.1.529 Virus Detected in Europe
}

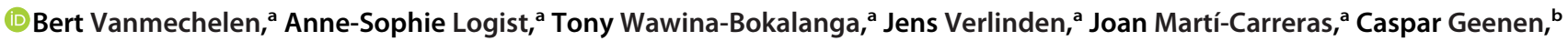 \\ Bram Slechten, ${ }^{b}$ Lize Cuypers, ${ }^{\mathrm{b}, \mathrm{c}}$ Emmanuel André, ${ }^{\mathrm{b}, \mathrm{c}}$ Guy Baele, ${ }^{\mathrm{a}}$ (D) Piet Maes $^{\mathrm{a}}$ \\ aKU Leuven, Department of Microbiology, Immunology, and Transplantation, Laboratory of Clinical and Epidemiological Virology, Rega Institute for Medical Research, \\ Leuven, Belgium \\ bKU Leuven, Department of Microbiology, Immunology, and Transplantation, Laboratory of Clinical Microbiology, National Reference Laboratories for COVID-19, Leuven, \\ Belgium \\ cUZ Leuven, Department of Laboratory Medicine, Leuven, Belgium
}

ABSTRACT We report the complete genome sequence of a severe acute respiratory syndrome coronavirus 2 (SARS-CoV-2) Omicron variant (lineage B.1.1.529) from a Belgian patient with a history of recent travel to Egypt. At the time of writing, this genome constituted the first confirmed case of an infection with the Omicron variant in Europe. n December 2019, a novel betacoronavirus, severe acute respiratory syndrome coronavirus 2 (SARS-CoV-2) (genus Betacoronavirus, subfamily Orthocoronavirinae, family Coronaviridae), was identified in Wuhan, China (1,2). Following its spread to the rest of the world, many unique mutations in the virus genome have been reported. The biological advantages conferred by some of these mutations have resulted in the establishment of specific genetic lineages that have largely outcompeted the original strain (3). Lineages that are characterized by increased transmissibility or virulence or that decrease the effectiveness of available countermeasures are classified by the WHO as variants of concern (VOCs) (4). On 26 November 2021, 2 days after it was reported for the first time in South Africa, a new lineage (B.1.1.529) was classified as variant Omicron, the fifth recognized VOC (5). Here, we report the genome sequence of the first reported Omicron variant in Europe.

The sample was collected as part of routine COVID-19 diagnostics and selected for whole-genome sequencing following an $S$ gene dropout in quantitative PCR (qPCR) testing (TaqPath COVID-19 CE-IVD reverse transcription [RT]-PCR kit; Thermo Fisher Scientific). This work was reviewed and approved by the KU/UZ Leuven Clinical Trial and Ethical review board (approval number S66037), which allows us to use patient samples for research and lookup and use specific metadata from the patient. The patient returned from Egypt to Belgium on 11 November 2021 and tested negative 3 days before travelling, as well as repeatedly testing negative during quarantine after arrival in Belgium. The patient developed mild symptoms 10 days after arrival and tested positive for SARS-CoV-2 on 24 November 2021. RNA was extracted from a nasopharyngeal swab sample using the QIAamp viral RNA minikit (Qiagen, Hilden, Germany), after which a barcoded Nanopore sequencing library was prepared using the COVID Midnight midikit (C19MIDI; Oxford Nanopore Technologies), which uses a tiled amplicon approach ( $\sim$ 1,200-bp amplicons) to amplify the SARS-CoV-2 genome. The library was sequenced for $72 \mathrm{~h}$ on an R9.4.1 flow cell. Base calling and demultiplexing were done using the GridION built-in MinKNOW software (v21.05.25), and the resulting reads were processed using the ARTIC bioinformatics pipeline v1.1.3 (6).

The genome sequence obtained has a total length of 29,684 nucleotides and a GC content of $38 \%$, with an average coverage depth of $1,501 \times$. Because the genome termini are not covered by the amplicons used, the 54 first (5') and 151 last ( $\left.3^{\prime}\right)$ nucleotides, compared to the SARS-CoV-2 reference genome (GenBank accession number NC_045512.2),
Editor Simon Roux, DOE Joint Genome Institute

Copyright $\odot 2022$ Vanmechelen et al. This is an open-access article distributed under the terms of the Creative Commons Attribution 4.0 International license.

Address correspondence to Piet Maes, piet.maes@kuleuven.be.

The authors declare no conflict of interest.

Received 1 December 2021

Accepted 25 December 2021

Published 3 February 2022 
TABLE 1 Mutations of SARS-CoV-2 strain hCoV-19/Belgium/rega-20174/2021 in comparison with the reference strain (GenBank accession number NC_045512.2)

\begin{tabular}{|c|c|c|c|c|}
\hline Gene or region ${ }^{a}$ & Nucleotide position(s) & $\begin{array}{l}\text { Amino acid } \\
\text { change }^{b}\end{array}$ & 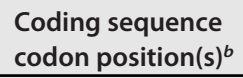 & $\begin{array}{l}\text { Nucleotide } \\
\text { change }^{b}\end{array}$ \\
\hline \multirow[t]{11}{*}{$\overline{\text { ORF1a }}$} & 241 & - & - & $\mathrm{C}$ to $\mathrm{T}$ \\
\hline & 2832 & $\mathrm{~K}$ to $\mathrm{R}$ & 856 & A to $G$ \\
\hline & 3037 & - & - & $\mathrm{C}$ to $\mathrm{T}$ \\
\hline & 5386 & - & - & $\mathrm{T}$ to $\mathrm{G}$ \\
\hline & $6513-6515$ & S deletion & 2083 & - \\
\hline & 8393 & A to $T$ & 2710 & $\mathrm{G}$ to $\mathrm{A}$ \\
\hline & 10029 & $\mathrm{~T}$ to $\mathrm{I}$ & 3255 & $\mathrm{C}$ to $\mathrm{T}$ \\
\hline & 10449 & $\mathrm{P}$ to $\mathrm{H}$ & 3395 & $C$ to $A$ \\
\hline & $11285-11293$ & LSG deletion & $3674-3676$ & - \\
\hline & 11537 & I to $\mathrm{V}$ & 3758 & A to $G$ \\
\hline & 13195 & - & - & $\mathrm{T}$ to $\mathrm{C}$ \\
\hline \multirow[t]{3}{*}{ ORF1b } & 14408 & $\mathrm{P}$ to $\mathrm{L}$ & 314 & $\mathrm{C}$ to $\mathrm{T}$ \\
\hline & 15240 & - & - & $\mathrm{C}$ to $\mathrm{T}$ \\
\hline & 18163 & I to $\mathrm{V}$ & 1566 & A to $G$ \\
\hline \multirow[t]{32}{*}{$\mathrm{S}$} & 21762 & - & - & $\mathrm{C}$ to $\mathrm{T}$ \\
\hline & $21765-21770$ & HV deletion & $69-70$ & - \\
\hline & 21846 & T to I & 95 & $\mathrm{C}$ to $\mathrm{T}$ \\
\hline & 21987-21995 & GVY deletion & $142-144$ & - \\
\hline & 22194-22196 & $\mathrm{N}$ deletion & 211 & - \\
\hline & 22578 & $G$ to $D$ & 339 & $\mathrm{G}$ to $\mathrm{A}$ \\
\hline & $22673-22674$ & $S$ to $L$ & 371 & $\mathrm{TC}$ to $\mathrm{CT}$ \\
\hline & 22679 & $S$ to $P$ & 373 & $T$ to $C$ \\
\hline & 22686 & $\mathrm{~S}$ to $\mathrm{F}$ & 375 & $\mathrm{C}$ to $\mathrm{T}$ \\
\hline & 22813 & $\mathrm{~K}$ to $\mathrm{N}$ & 417 & $\mathrm{G}$ to $\mathrm{T}$ \\
\hline & 22882 & $\mathrm{~N}$ to $\mathrm{K}$ & 440 & $\mathrm{~T}$ to $\mathrm{G}$ \\
\hline & 22898 & $\mathrm{G}$ to $\mathrm{S}$ & 446 & $\mathrm{G}$ to $\mathrm{A}$ \\
\hline & 22992 & $\mathrm{~S}$ to $\mathrm{N}$ & 477 & $\mathrm{G}$ to $\mathrm{A}$ \\
\hline & 22995 & $\mathrm{~T}$ to $\mathrm{K}$ & 478 & $\mathrm{C}$ to $\mathrm{A}$ \\
\hline & 23013 & $E$ to $A$ & 484 & A to $C$ \\
\hline & 23040 & $Q$ to $R$ & 493 & A to $G$ \\
\hline & 23048 & $\mathrm{G}$ to $\mathrm{S}$ & 496 & $\mathrm{G}$ to $\mathrm{A}$ \\
\hline & 23055 & $Q$ to $R$ & 498 & A to $G$ \\
\hline & 23063 & $\mathrm{~N}$ to $\mathrm{Y}$ & 501 & A to $T$ \\
\hline & 23075 & $\mathrm{Y}$ to $\mathrm{H}$ & 505 & $\mathrm{~T}$ to $\mathrm{C}$ \\
\hline & 23202 & $\mathrm{~T}$ to $\mathrm{K}$ & 547 & $\mathrm{C}$ to $\mathrm{A}$ \\
\hline & 23403 & $D$ to $G$ & 614 & A to $G$ \\
\hline & 23525 & $\mathrm{H}$ to $\mathrm{Y}$ & 655 & $\mathrm{C}$ to $\mathrm{T}$ \\
\hline & 23599 & $\mathrm{~N}$ to $\mathrm{K}$ & 679 & $\mathrm{~T}$ to $\mathrm{G}$ \\
\hline & 23604 & $\mathrm{P}$ to $\mathrm{H}$ & 681 & $\mathrm{C}$ to $\mathrm{A}$ \\
\hline & 23854 & $\mathrm{~N}$ to $\mathrm{K}$ & 764 & $\mathrm{C}$ to $\mathrm{A}$ \\
\hline & 23948 & $D$ to $Y$ & 796 & $\mathrm{G}$ to $\mathrm{T}$ \\
\hline & 24130 & $\mathrm{~N}$ to $\mathrm{K}$ & 856 & $\mathrm{C}$ to $\mathrm{A}$ \\
\hline & 24424 & $\mathrm{Q}$ to $\mathrm{H}$ & 954 & A to $T$ \\
\hline & 24469 & $\mathrm{~N}$ to $\mathrm{K}$ & 969 & $\mathrm{~T}$ to $\mathrm{A}$ \\
\hline & 24503 & $\mathrm{~L}$ to $\mathrm{F}$ & 981 & $\mathrm{C}$ to $\mathrm{T}$ \\
\hline & 25000 & - & - & $\mathrm{C}$ to $\mathrm{T}$ \\
\hline ORF3a & 25584 & - & - & $\mathrm{C}$ to $\mathrm{T}$ \\
\hline E & 26270 & $\mathrm{~T}$ to I & 9 & $\mathrm{C}$ to $\mathrm{T}$ \\
\hline \multirow[t]{3}{*}{ M } & 26530 & $D$ to $G$ & 3 & A to $G$ \\
\hline & 26577 & $\mathrm{Q}$ to $\mathrm{E}$ & 19 & $C$ to $\mathrm{G}$ \\
\hline & 26709 & A to $T$ & 63 & $\mathrm{G}$ to $\mathrm{A}$ \\
\hline ORF6 & 27259 & - & - & A to $C$ \\
\hline ORF7b & 27807 & - & - & $\mathrm{C}$ to $\mathrm{T}$ \\
\hline \multirow[t]{3}{*}{$\mathrm{N}$} & 28271 & - & - & A to $T$ \\
\hline & 28311 & $P$ to $L$ & 13 & $\mathrm{C}$ to $\mathrm{T}$ \\
\hline & $28362-28370$ & ERS deletion & $31-33$ & - \\
\hline ORF9b & $28362-28370$ & ENA deletion & $27-29$ & - \\
\hline $\mathrm{N}$ & $28881-28883$ & $\mathrm{RG}$ to $\mathrm{KR}$ & $203-204$ & GGG to AAC \\
\hline
\end{tabular}

${ }^{a} \mathrm{ORF}$, open reading frame.

$b$ - no amino acid or codon change occurred, and no nucleotide change occurred when a deletion was detected. 
hCoV-19/South_Africa/CERI-KRISP-K032189/2021IEPI_ISL_6699729|2021-11-17 - hCoV-19/South_Africa/NICD-N21671/2021IEPI_ISL 670487012021-11-20 - hCoV-19/South_Africa/CERI-KRISP-K032221/2021IEPI_ISL_6699750I2021-11-19

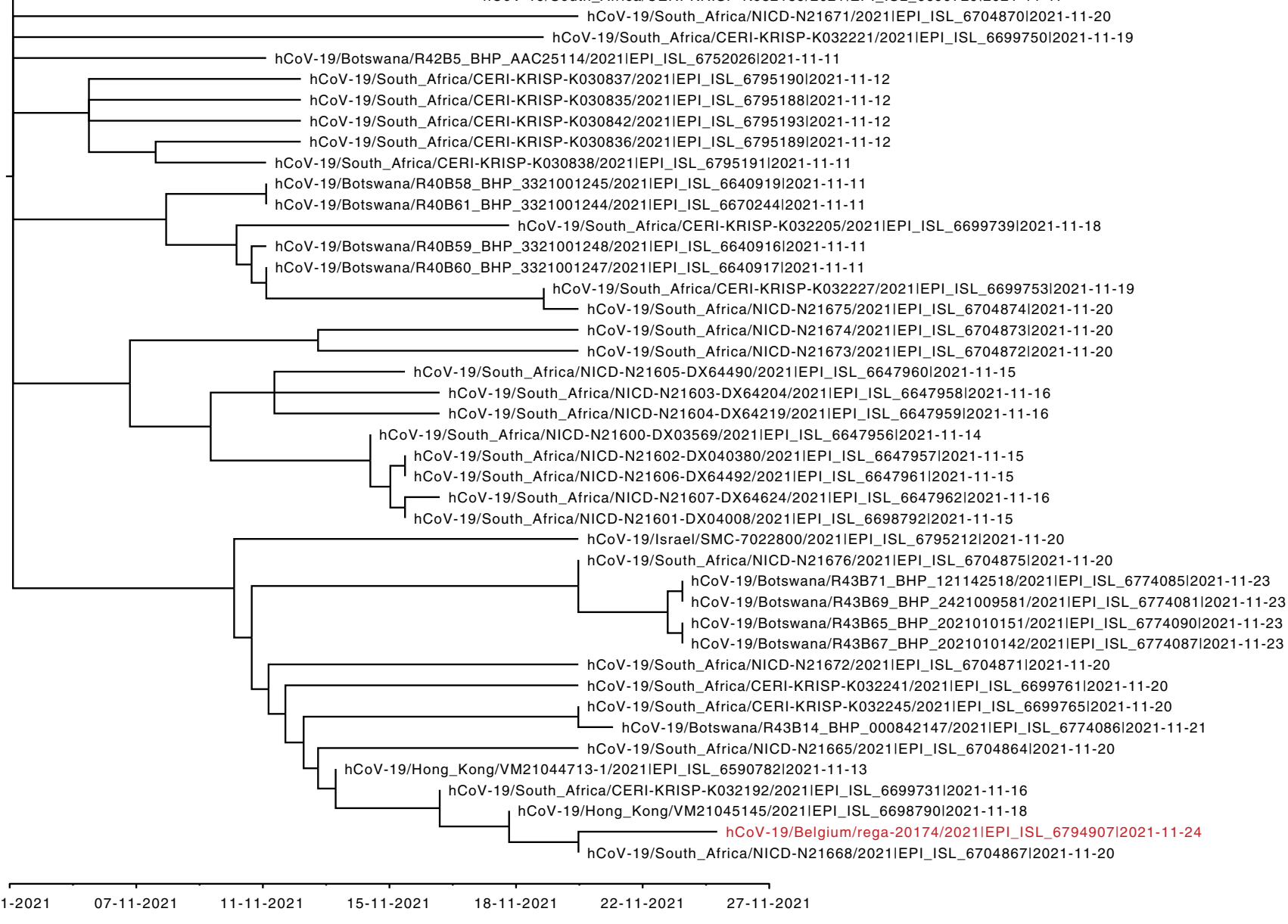

FIG 1 Time-calibrated phylogenetic tree of strain hCoV-19/Belgium/rega-20174/2021 (highlighted in red) in a clade of the most closely related Omicron variant sequences (black). EPI_ISL_ numbers in the entries are GISAID accession numbers.

are not present in this sequence. Nextclade v1.10.0 was used for comparison with the RefSeq sequence (7). This genome contains 54 mutations and 39 indels (Table 1), compared to the RefSeq sequence, highlighting the strong divergence of this novel variant.

A phylogenetic analysis was performed using all available B.1.1.529 genomes in GISAID on 27 November 2021, along with a few representative genomes of the different VOCs (to root the phylogeny). MAFFT v7.475 was used to align the genome sequences, and the initial tree was generated using IQ-TREE v2.1.3 with automated model selection $(8,9)$. Following inspection of the resulting phylogeny using TempEst v1.5.3, nine outliers were removed to allow the subsequent estimation of a time-calibrated phylogeny using TreeTime v0.8.1 $(10,11)$. The resulting tree was visualized using FigTree v1.4.4 (Fig. 1). The phylogenetic analysis shows that the sequence reported here, hCoV-19/Belgium/rega-20174/2021, clusters as part of a larger clade with South African cases, the two previously confirmed cases from Hong Kong, and the one confirmed case from Israel.

Data availability. This sequence has been deposited in GISAID (accession number EPI_ISL_6794907) and GenBank (accession number OL672836). The accession numbers for the raw sequencing reads in the NCBI Sequence Read Archive (SRA) are PRJNA784547 and SRR17066006.

\section{ACKNOWLEDGMENTS}

This work and the sequencing capacity were supported in part by a COVID19 research grant from the Research Foundation Flanders (grant G0H4420N) and by an Internal Funds KU Leuven grant awarded to P.M. (grant 3M170314). G.B. acknowledges support from 
Internal Funds KU Leuven (grant C14/18/094) and the Research Foundation Flanders (grants G0E1420N and G098321N). UZ Leuven, as a national reference center for respiratory pathogens, is supported by Sciensano, which is gratefully acknowledged.

\section{REFERENCES}

1. Coronaviridae Study Group of the International Committee on Taxonomy of Viruses. 2020. The species Severe acute respiratory syndrome-related coronavirus: classifying 2019-nCoV and naming it SARS-CoV-2. Nat Microbiol 5:536-544. https://doi.org/10.1038/s41564-020-0695-Z

2. Zhu N, Zhang D, Wang W, Li X, Yang B, Song J, Zhao X, Huang B, Shi W, Lu R, Niu P, Zhan F, Ma X, Wang D, Xu W, Wu G, Gao GF, Tan W, China Novel Coronavirus Investigating and Research Team. 2020. A novel coronavirus from patients with pneumonia in China, 2019. N Engl J Med 382:727-733. https://doi.org/10.1056/NEJMoa2001017.

3. Mullen JL, Tsueng G, Latif AA, Alkuzweny M, Cano M, Haag E, Zhou J, Zeller M, Hufbauer E, Matteson N, Andersen KG, Wu C, Su Al, Gangavarapu K, Hughes LD, Center for Viral Systems Biology. 2020. outbreak.info. https:// outbreak.info. Accessed 29 November 2021.

4. World Health Organization. 2021. Tracking SARS-CoV-2 variants. https://www .who.int/en/activities/tracking-SARS-CoV-2-variants. Accessed 29 November 2021.

5. World Health Organization. 2021. Classification of Omicron (B.1.1.529): SARS-CoV-2 variant of concern. https://www.who.int/news/item/26-11-2021 -classification-of-omicron-(b.1.1.529)-sars-cov-2-variant-of-concern. Accessed 29 November 2021.
6. Loman N, Rowe W, Rambaut A. 2020. nCoV-2019 novel coronavirus bioinformatics protocol. https://artic.network/ncov-2019/ncov2019-bioinformatics-sop .html. Accessed 29 November 2021.

7. Hadfield J, Megill C, Bell SM, Huddleston J, Potter B, Callender C, Sagulenko P, Bedford T, Neher RA. 2018. Nextstrain: real-time tracking of pathogen evolution. Bioinformatics 34:4121-4123. https://doi.org/10.1093/bioinformatics/ bty407.

8. Nguyen LT, Schmidt HA, von Haeseler A, Minh BQ. 2015. IQ-TREE: a fast and effective stochastic algorithm for estimating maximum-likelihood phylogenies. Mol Biol Evol 32:268-274. https://doi.org/10.1093/molbev/ msu300.

9. Katoh K, Standley DM. 2013. MAFFT multiple sequence alignment software version 7: improvements in performance and usability. Mol Biol Evol 30:772-780. https://doi.org/10.1093/molbev/mst010.

10. Sagulenko P, Puller V, Neher RA. 2018. TreeTime: maximum-likelihood phylodynamic analysis. Virus Evol 4:vex042. https://doi.org/10.1093/ve/ vex042.

11. Rambaut A, Lam TT, Carvalho LM, Pybus OG. 2016. Exploring the temporal structure of heterochronous sequences using TempEst (formerly Path-OGen). Virus Evol 2:vew007. https://doi.org/10.1093/ve/vew007. 